\title{
The Development of Academic Self-Efficacy Scale for Filipino Junior High School Students
}

\author{
Angelo Reyes Dullas ${ }^{1,2 *}$ \\ ${ }^{1}$ Psychology, Central Luzon State University, Muñoz, Philippines, ${ }^{2}$ University of Santo Tomas, Manila, Philippines
}

\section{OPEN ACCESS}

Edited by:

Jesus de la Fuente, University of Almería, Spain

Reviewed by: Caterina Fiorilli, Libera Università Maria SS. Assunta, Italy Melissa Christine Davis, Curtin University, Australia

*Correspondence: Angelo Reyes Dullas dullas.angelo@yahoo.com

Specialty section: This article was submitted to Educational Psychology, a section of the journal Frontiers in Education

Received: 18 October 2017 Accepted: 08 March 2018 Published: 04 April 2018

Citation:

Dullas AR (2018) The Development of Academic Self-Efficacy Scale for Filipino Junior High School Students.

Front. Educ. 3:19.

doi: 10.3389/feduc.2018.00019
Primarily the research is focused on the development and validation of the Academic Self-efficacy Scale (ASES-FJHS) for Filipino junior high school students. Self-efficacy refers to people's beliefs in their capabilities to produce certain effects and to learn or perform behaviors at designated levels (Bandura, 2006, 2012). In relation to test construction, most of the developed self-efficacy scale focuses on one source of selfefficacy and are constructed as subscale. Given the limited published ASES for Filipino junior high school students as well as the non-existence of published and established ASES in Philippine context, this study sought to develop and validate a self-efficacy scale that is more holistic than those previously published. The design of the research is Test Development and anchored on Classical Test Theory. Respondents comprised of 4,759 junior high school students from selected 20 public and private schools in Nueva Ecija, Philippines. The study followed the two stages of test development, i.e., the development of the initial, preliminary, and final forms and validation of the scale. The items were developed through consultation with experts and literature reviews. After the development of table of specification, items were validated by four expert judges. Results showed using Lawshe Content Validation Ratio $(\mathrm{CVI}=0.87)$ and Intra-class Correlation [ICC $(2,4)=0.953, a=0.000]$ that the expert validators have high agreement on the items of ASES. Moreover, Upper Limit-Lower Limit method $(d=0.43)$, Cronbach alpha (0.95), split-half method (Spearman-Brown Coefficient $=0.86$ ), item to total correlation, and Principal Component Analysis were also utilized to test the reliability of test items. The factor structure verified the four iterations which includes perceived control $(\mathrm{PC})$, competence $(\mathrm{C})$, persistence $(\mathrm{P})$, and self-regulated learning domains. Convergent $(r=0.498 ; p<0.05)$ and concurrent validity $(r=0.518 ; p<0.01)$ that were employed suggest that the ASES is a valid measure. The Final Form validated consists of 62 items. Results of the study revealed that the ASES for $\mathrm{K}$ to 12 junior high school students is a reliable and valid measure of Academic Self-efficacy.

Keywords: academic self-efficacy, $\mathrm{K}$ to 12 curriculum, test construction, Filipino junior high school students, high school self-efficacy

\section{INTRODUCTION}

The idea of self-efficacy refers to people's beliefs in their capabilities to produce certain effects and to learn or perform behaviors at designated levels (Bandura, 1997; Schunk and Pajares, 2002). More than that, it is also a belief about what a person can do rather than a person's judgments about one's physical or personality attributes (Zimmerman and Cleary, 2006). Lent (2005) nevertheless notes 
that self-efficacy is linked to particular performance domains and activities and is thus crucial to human functioning.

A key idea, however, in human functioning is perceived efficacy. Albert Bandura (1997) for example argues that the impact of perceived efficacy plays a key role in human functioning. Included here for instance are goals, aspirations, outcome expectations, affective proclivities, and perception of impediments and opportunities in the social environment. It is, therefore, concerned with people's beliefs in their capabilities to exercise control over their own functioning and over events that affect their lives. Bandura (1997) in fact argues that beliefs in personal efficacy affect life choices, level of motivation, quality of functioning, resilience to adversity and vulnerability to stress and depression. In the same way, Brown et al. (2013) argue that perceived efficacy also influences the individuals' different degrees of confidence in their abilities in different diverse domains of tasks. Efficacy beliefs, in addition, influence whether people think erratically or strategically, optimistically or pessimistically (Schunk and Pajares, 2002).

Zimmerman and Cleary (2006), however, comment that selfefficacy is context-specific and varies across several dimensions, such as level, generality, and strength. The level of self-efficacy refers to its dependence on the difficulty level of a particular task (such as math addition problems of increasing difficulty); while generality of self-efficacy belief refers to the transferability of one's efficacy judgments across different tasks or activities; and strength of efficacy judgment pertains to the certainty with which one can perform a specific task.

In the school context, self-efficacy is one of the strongest predictor of student's academic performance (Klomegah, 2007). It is a belief that he or she can accomplish whatever that individual is doing. Self-efficacy is the process from person to behavior to outcome (Brown et al., 2013). Moreover, students' self-efficacy beliefs influence the choices they make and the effort they put in their performance (Boekaerts and Cascallar, 2006). Also, selfefficacy plays an important role in a student's engagement in the classroom. When facing need, students with high self-efficacy tend to manifest high help seeking behavior; whereas students with low self-efficacy are more reluctant to seek help (Nelson and Ketelhut, 2008). Students who have positive and relatively high self-efficacy beliefs will more likely engage in the classroom in terms of their behavior, cognition, and motivation (Linnenbrink and Pintrich, 2003); and that the higher academic self-efficacy the students have, the higher their metacognitive awareness (Hermita and Thamrin, 2015). In addition, self-efficacious students have higher academic performance for they regulate and monitor their impulses effectively in facing academic challenges (Komarraju and Nadler, 2013). Moreover, in predicting desirable educational outcome, academic self-efficacy has greater effect or influence on students' ability than academic self-concept (Jansen et al., 2015).

\section{Sources of Self-Efficacy}

People's beliefs in their self-efficacy are developed by their four main sources of influence. These include mastery experiences, vicarious experiences or seeing another person similar to oneself managing task successfully, social persuasion, that one has the capabilities and somatic and emotional states in which ordinary realities are strewn with impediments, adversities, setbacks, frustration, and inequities which have important contribution to self-efficacy belief (Bandura, 1994, 1997).

Lent (2005) suggested that of the four sources of information or learning experience, personal performance accomplishments has the most powerful influence on the status of self-efficacy. This source leads to a development of self-efficacy for a given behavior or domain of behavior (Bandura, 1994, 1997, 2006). Mastery of experience or the results of one's own previous attainment are gained not only on easy successes but in overcoming obstacles through perseverant effort. In addition, when a person experiences difficulties and setbacks and learns to overcome these hindrances, he becomes resilient and later acquires the necessary experience needed to overcome difficult tasks (Bandura, 1994). Vicarious experiences, on the other hand, serve as a source of self-efficacy through social modeling. In the academic context, seeing people similar to oneself succeed by sustained effort raises observers' beliefs that they too possess the capabilities, master comparable activities to succeed (Bandura, 1994, 1997; Usher and Pajares, 2009). Social persuasion is the third source of self-efficacy which emphasizes the belief that when people are persuaded verbally they will possess the capabilities to master given activities and are likely to mobilize greater effort and sustain it than if they harbor self-doubts and dwell on personal deficiencies when problems arise.

Fourth source relies partly on somatic and emotional states in judging capabilities. The goal is to reduce people's stress reactions and alter negative emotional proclivities and misinterpretations of their physical states (Bandura, 1994). However, in the context of academic setting, Usher and Pajares (2009) contended that an effective way of measuring physiological arousal among high school and college students is by measuring the anxiety level on academic related subjects.

\section{Development of Self-Efficacy Scales}

In relation to test development focusing on academic self-efficacy, most of the constructed self-efficacy scale in the academic context are usually either a subscale or part of a scale (Harter, 1985; Pintrich and De Groot, 1990; Jinks and Morgan, 1999; Midgley et al., 2000; Anderman et al., 2005). This only means that most of the existing self-efficacy scales in the academic setting are actually part of much larger scale. Example is the Patterns of Adaptive Learning by Midgley et al. (2000) wherein the measure selfefficacy is just a subscale. Moreover, existing self-efficacy scale focuses on only one source of self-efficacy such mastery experiences, vicarious experiences, social persuasion, or perhaps somatic and emotional states (Harter, 1985; Pintrich and De Groot, 1990; Jinks and Morgan, 1999; Midgley et al., 2000; Anderman et al., 2005; Chen and Usher, 2013). This trend is also seen with studies of Do-Hong et al. (2015) and Huang (2013) on their development and validation of academic self-efficacy scale (ASES) on Asian cultures. Do-Hong et al. (2015) for example, examine the source of self-efficacy mastery experiences on the development of Science related efficacy scale among Asian samples.

Although most of the developed self-efficacy scale focuses on one source of self-efficacy, self-efficacy researchers explored concepts and variables that are primarily linked to self-efficacy per se. These are self-regulated learning (SRL), perceived control 
(PC) or internal locus of control, persistence, and competence. The constructed domains of academic self-efficacy are based on the careful reading of the researcher on the existing literatures on the application of self-efficacy concept in the context of academic setting. The concepts of SRL, Persistence, and Competence are considered as part of the self-efficacy based on different studies (Bandura, 1994, 1997; Schwarzer, 1998, 2001; Schunk and Pajares, 2002; Zimmerman, 2008; Zimmerman and Schunk, 2008; Salmeron et al., 2010; Feist et al., 2013; Schnell et al., 2015). In addition, PC or locus of control is highly correlated and has significant impact on academic self-efficacy among students (Bandura, 1994, 1997; Schunk and Pajares, 2002; Zimmerman and Cleary, 2006; Coutinho, 2008; Kleitman and Gibson, 2011; Feist et al., 2013; Hermita and Thamrin, 2015).

\section{Self-Regulated Learning}

One of the major constructs with established correlation in the context of academic self-efficacy is SRL (Bandura, 1994, 1997; Zimmerman, 2008; Zimmerman and Schunk, 2008; Salmeron et al., 2010; Schnell et al., 2015). Self-regulation, according to Zimmerman (2008) is defined as self-generated thoughts, feelings, and actions which are planned and cyclically adapted to attain personal goals. Furthermore, SRL refers to self-governing processes and self-beliefs that facilitate transformation of mental abilities into school performance abilities (Zimmerman, 2008). Application of self-regulation in learning or SRL according to Zimmerman (2008) and Zimmerman and Schunk (2008) on (a) students as active in their learning process, and (b) successful use of self-regulating strategies in certain areas that depend on the quantity and quality of the interaction, between the student and the subject. Moreover, Cazan (2012) found out that a student who is high on self-regulation can plan proficiently, monitor his or her learning process and progress, constantly adjust his/her behavior to the requirements of learning situations, perform better and have higher levels of academic adjustments which are all integral part of a student's academic success. In addition, Zimmerman and Schunk (2008) found reciprocal relationship between self-efficacy beliefs and self-regulation. They found out that as students increased their self-efficacy belief, their self-regulation capacity also increased, which also allowed the students to face further academic challenges (Diseth, 2011).

\section{PC or Internal Locus of Control}

Perceived control or Internal Locus of Control, a concept by Julian Rotter, is one of the five subcomponents of Self-efficacy. It explains why some people believe that rewards are the consequences of their own behavior. In relation to self-efficacy, people with an internal locus of control possess the same characteristics such as attributions of failures and successes as caused by the self and belief that they can alter behavior as they desire (Feist et al., 2013). People who perceive whatever happens to them are not in the hands of fate, luck, or chance exhibit an internal locus of control (Wood and Wood, 1996). They have intrinsic motivation which is also evident in people with high self-efficacy (Bandura, 1994, 1997). Moreover, PC is one aspect of self-efficacy. It is relevant to selfefficacy in the sense that perceptions of ability, social comparison, attributions, time available, and perceived importance are factors of PC that influences self-efficacy just the same (Bandura, 1994, 1997; Schunk and Pajares, 2002; Zimmerman and Cleary, 2006).

\section{Persistence}

Studies on the functional relationship between persistence and academic self-efficacy showed strong correlation (Pajares and Miller, 1994; Schunk and Pajares, 2002; Schnell et al., 2015). In fact, some self-efficacy researchers (Schwarzer, 1998; Schunk and Pajares, 2002) conceptualized persistence or perseverance as strategy and part of self-efficacy to continue in attaining goal-oriented behavior despite academic obstacles and negative academic experiences. People with high persistence have little fear of the unknown, are able to stand up for what they believe in, and have the courage to face whatever may come along. This is related to the fact that most confident people are also persistent and that they have the courage to pull through any circumstances. In relation to self-efficacy, persistence strongly influence the choices people make, the effort they expend, the strength of their perseverance in the face of adversity, and the degree of anxiety they experience (Bandura, 1994, 1997). And those students with high self-efficacy increase the monitoring of their performances which leads to greater persistence of their positive academic behaviors (Bouffard et al., 2005).

\section{Competence}

Competence is another subdomain of Self-efficacy. According to Wigfield and Eccles (2000) expectancy and ability beliefs are judgments of students' competence and their self-efficacy. Expectency beliefs and ability beliefs both consist of expectations for success and perceptions of competence. Expectancy beliefs have items that ask students on how well they will do in an academic area or learn new material, while ability beliefs have items that ask how good a student is in an academic subject, how they rate themselves and how good they are in that subject compared with other classmates (Wigfield and Eccles, 2000). In addition, according to Schunk (1995) and Schunk and Pajares (2002) domain and specific and task specific are the levels of specificity of self-competence and self-efficacy. Expectancy and ability beliefs falls on domain specific while self-efficacy beliefs fall on task specific, but are sometimes assessed at a domain-specific level. Furthermore, students with high self-efficacy focus on enhancing their competencies and learning tasks (Khezriazara et al., 2010). It is ability, capacity, competence, faculty, and might. With more competence comes more ability to control the future and attribute events as caused by the self, thus exhibit personal efficacy (Feist et al., 2013). In addition, students with high self-efficacy center on enhancing their competencies and learning tasks (Khezriazara et al., 2010).

In relation with the current study, these four factors of self-efficacy becomes the basis for the development of ASES for Filipino Junior High School Students. There is also no published and established ASES in Philippine context from where are the Filipino junior high school students are the major concerns. This is an important consideration in test construction as Bandura (2006), Zimmerman and Cleary (2006), and Schunk and Pajares (2002) emphasized that the context and the specificity of the domains are important considerations in constructing self-efficacy scale. With 
the implementation of the $\mathrm{K}$ to 12 curriculum in the Philippines, which added 2 years in the basic education level, the students are the most affected ones. This compels students to extend their investments and resources in education. As a matter of policy, schools are required to deliver a curriculum that is in line with national standards (Department of Education, 2012; Order No. 31, S. 2012). Among the many changes brought about by the new educational policy is the assessment of students' beliefs about their competencies.

\section{Theoretical Framework: Bandura's Social Cognitive Theory}

Bandura's Social Cognitive theory emphasizes the relevance and interactions of environment, person's variable and behaviors both in personality and learning. The triadic causation model emphasizes that human functioning is the product of the interaction between (B) behavior, $(\mathrm{P})$ person's variable, and (E) environment. Reciprocal means not similar or opposite rather than expressing the triadic interaction of the three variables. Person's variable includes cognitive factors such as beliefs, memory, planning, and judging. By cognitive functions, people have the capacity to select or choose to attend from the environment or what to give value for example. However, cognition and behavior are not separate entity for those cognitive processes which are formed both by behavior and environment (Feist et al., 2013).

\section{Purpose of the Study}

Based from the current literatures most of the developed ASES focuses on one source of self-efficacy (Chen and Usher, 2013; Huang, 2013; Do-Hong et al., 2015) and constructed as subscale (Harter, 1985; Pintrich and De Groot, 1990; Jinks and Morgan, 1999; Midgley et al., 2000; Anderman et al., 2005). Thus, the major objective of the study is to develop, identify, validate, and find the reliability of item composition of ASES (ASES-FJHS) for Filipino Junior high school students, emphasizing new factors associated with academic self-efficacy.

\section{MATERIALS AND METHODS}

\section{Research Design}

The design of the research was in the form of Test Development and anchored on Classical Test Theory which is the basic approach and guide in test construction (Rust and Golombok, 1992; Kline, 1993; Cohen et al., 2013).

\section{Participants}

The study was conducted among high school students in Grades 7 to 10 from the selected private and public high schools in Nueva Ecija, Philippines. The age bracket was 11-16 years old. Participants of the study were subdivided based on the two stages employed in the study-i.e., development of ASES-FJHS final and the validation of the scale. The first stage involves three processes: initial, preliminary, and final form. In the initial development of the scale, participants includes four expert item validators, one is a certified Educational Psychologist, one Clinical Psychologists, one Guidance Counselor, and one High School Principal.
Moreover, 400 participants were employed for initial testing. After analyzing the result of pilot testing, the Preliminary Form was administered to 3,909 participants, of which 1,922 are males (49.2\%) and 1,987 (50.8\%) are females from the 20 public (10) and private (10) high schools in Nueva Ecija. 1,845 (47.2\%) of the respondents came from public schools and 2,064 (52.8\%) from private schools. In terms of representative per year level, 980 (25.1\%) students came from 7 th grade, $969(24.8 \%)$ students from 8 th grade, 981 (25.1\%) from 9th grade, and 979 (25\%) from 10th grade. After the development of the final form, the second stage was validation process. The ASES-FJHS was validated to 450 junior high school students using Bandura's Children's Self-efficacy Scale for convergent and Grade Weighted Average (GWA) of the participants for concurrent validity.

\section{Procedure}

The data gathering procedure was divided to two stages. The first part which is the development stage involves into three processes: the development of the initial, preliminary, and the final form. Test construction utilizes expert judges in establishing content validity of test items (Cohen et al., 2013). In this study, item validators were composed of four experts. The validators endorsed the items based on how they perceived and judged each items using the format "Accepted (2), Needs Revision (1), Rejected (0)." Participants evaluate the items separately, thus adhering to the idea of single blind procedure. Their scores were tabulated. Statistical tools such as Content Validation Ratio (CVR) and intraclass correlation were utilized. Afterward, the initial form was developed. The initial survey was administered to 400 respondents. After analyzing the result of pilot testing, the Preliminary Form was developed. It was further administered to 3,909 participants. Using different reliability measures and Principal component analysis the data were further analyzed. The second stage is the validation of the scale. The developed Final Form was validated using convergent and concurrent validity to 450 junior high school students. In the convergent validity, the Children's Self-Efficacy Scale (Bandura, 2006) was used. The CSES measures academic efficacy of students with norming on secondary high schools (until grade 10). In addition, concurrent validity was established by correlating the GWA of the students to their scores on ASES Final Form at the same time. Table A1 presents the items of ASES-FJHS.

\section{Ethics Review and Informed Consent}

Before conducting the research, the paper was submitted to review by the Ethics Review Committee of the University of Santo Tomas Graduate School, UST, Manila, Philippines. After intensive review of the research, the committee granted its approval for the conduct of the study (see Data Sheet 1 in Supplementary Material). Moreover, the researcher also offered informed consent for the participants of the study which includes clause for confidentiality, voluntariness, consent for the participants and the participant's parent consent since the participants of the study are minors (see Data Sheet 2 in Supplementary Material for detailed information about the participant's informed consent).

\section{Data Analysis}

The study used statistical analysis for the following objectives: 
For the development of initial form, mean, SD, CVR and intraclass correlation were utilized. For the reliability, validity, and item analysis of the Preliminary Form, Upper Limit-Lower Limit (UL-LL) method, item discrimination index, and Cronbach alpha analysis were used. In terms of Split-half, Spearman-Brown Coefficient and Guttman Split-Half Coefficient were employed. For identifying the items that would compose the ASES in its final form, Principal component analysis was used. For the reliability analysis on Final form, Cronbach alpha and Item-Total Correlation were used. And for the validation-convergent and concurrent validity, Pearson $r$ correlation coefficient was used.

\section{RESULTS}

\section{Item Composition, Development, and Reliability Analysis of the ASES (ASES- FHS) for Filipino High School Students}

This part of the paper discusses item composition in terms of its development, reliability analysis, and validation of the ASES-FJHS.

On the first stage, development of items, the initial item composition of the ASES-FHS is 240. The scale has four domains namely: PC, Competence (C), Persistence (P), and SRL. Each domain has 60 items in the form of 4-point likert scale. Basically, the domains of the ASES-FJHS were determined through rigorous process of literature review and consultation from the experts. Items were reviewed by item validators composed of four experts, i.e., one Registered Psychologists, one Registered Guidance Counselor, one Certified Educational Psychologists, and one high school principal. The validators endorsed the items based on how they perceived and judged each items using the format "Accepted (2), Needs Revision (1), Rejected (0)." Participants evaluate the items separately, thus adhering to the idea of single blind procedure. Using CVR, scores of validators on the items were analyzed. For the implementation of CVR, each item must reach a CVR equal to or more than 0.75 to be included in the initial form. 20 items obtained less than.75 CVR. Thus, these items were eliminated from the pool of items. Moreover, Content Validation Index was also obtained. Overall CVI of ASES-FJHS in its initial form is 0.87

Further analysis was done on the scores of expert judges using intraclass correlation (ICC). Intraclass correlation discusses the consistency or agreement of raters or judges on the items of the scale/test (Landers, 2015), in this case the ASES in which the computed ICC $(2,4)=0.953$ with four raters across items (see Table A2 in Appendix). This means 95.3\% of the variance in the mean of these raters is "real." The analysis pertains that $95.3 \%$ of the items agreed on the four validators or that they have agreement on the items that were deleted and items that were accepted.

After the development and analysis of the Initial Draft the researcher conducted the pilot testing to 400 Junior High School Students located in Nueva Ecija. To analyze the result of the initial form, UL-LL or the extreme method is utilized for item analysis. The 220 items of the ASES were further analyzed using this approach. Results showed that eight items were eliminated from the ASES-FJHS. Two items were deleted from PC domain, additional two items on Competence domain, and four items on
Persistence domain. The eliminated items had the discrimination index of less than 0.20 . The discrimination index of the whole ASES on the other hand is 0.45 . In addition the difficulty index of the scale is 0.73. Both indices indicate that the ASES for Filipino Junior High School Students has the capacity to discriminate or distinguish between high performers from the low performers of students' perceived belief about their academic performance.

Results showed that the Cronbach alpha coefficient of the ASES Initial form is 0.981 . This indicates that the initial form of the ASES-FJHS has very high reliability. However, a very high level of Cronbach alpha also indicates that there are similar or repeated items used in a certain scale. Thus, it is required to identify and eliminate the items that have almost similar construction. The researcher revisits those items and eliminates items with similar construction. Moreover, using item-total correlation, items with weak correlation with the total score were also deleted. Combining the total items with weak $r$ coefficient and with similar construction, 142 items were eliminated. A total of 70 items remained from the pool of items.

The 70 items was subjected to 3,909 participants. The researcher used the method of Principal Component Analysis. Since there are predetermined factors, the researcher used Principal Component Analysis to validate if the four factors namely PC, Persistence (P), Competence (C), and SRL are the real composition of ASES-FJHS. Results showed that the correlation coefficients were above 0.30 and the Kaiser-Myer Olkin (KMO) index of sampling adequacy is 0.97 . In addition Bartlett's test of sphericity showed statistically significant result. Thus, the assumptions were met before conducting the factor analysis.

After verifying the assumptions, factor structure was analyzed using principal component and varimax rotation solutions involving four factors and factor loadings of the ASES-FJHS Final Form (see Table A3 in Appendix). Items that failed to load at 0.30 value or higher were eliminated. Moreover, result of the Eigenvalues accounted for $61 \%$ of the total variance and the screen test was consistent with the four iterations.

After the factor analysis, eight items were further eliminated. Five items were eliminated from PC domain, two from Competence (C), and one from Persistence (P) domain. A total of 62 items are the present composition of ASES Final Form. Table 1 presents the development of the Table of Specification of ASES.

Moreover, reliability analyzes showed positive results. Cronbach alpha, Item-Total Correlation, and Split-half method specifically Guttman and Spearman-Brown Coefficient were utilized for reliability analysis. Result of cronbach alpha of the ASES-FJHS for final form is 0.95 for standardized items. Thus, the

TABLE 1 | Table of specification of ASES-FJHS from the Original Form to Final Form.

\begin{tabular}{|c|c|c|c|c|}
\hline & $\begin{array}{l}\text { Original } \\
\text { form }\end{array}$ & $\begin{array}{l}\text { Initial } \\
\text { form }\end{array}$ & $\begin{array}{l}\text { Preliminary } \\
\text { form }\end{array}$ & $\begin{array}{l}\text { Final } \\
\text { form }\end{array}$ \\
\hline $\begin{array}{l}\text { Academic Self-efficacy Scale } \\
\text { (ASES) total }\end{array}$ & 240 & 220 & 212 & 62 \\
\hline Perceived control & 60 & 55 & 53 & 12 \\
\hline Competence (C) & 60 & 54 & 52 & 15 \\
\hline Persistence $(\mathrm{P})$ & 60 & 56 & 52 & 15 \\
\hline Self-regulated learning & 60 & 55 & 55 & 20 \\
\hline
\end{tabular}


elimination of the redundant items made the Final Form more reliable and internally consistent. The Cronbach alpha revealed that the domains of ASES-FJHS Final Form for PC, Competence, Persistence, and SRL are $0.831,0.853,0.901$, and 0.918 , respectively. These results imply that the individual domains of ASES-FJHS are highly reliable in terms of internal consistency. In terms of itemtotal correlation, most of the items have a correlation coefficient of $0.3-0.6$ which indicate moderate to strong correlation. Results showed that the domain of PC has items correlation coefficient ranging from 0.348 to 0.528 . Competence domain has its items correlation coefficient from 0.313 to 0.570 , while Persistence and SRL domain have items correlation coefficient from 0.442 to 0.597 and 0.410 to 0.631, respectively (see Table A4 in Appendix).

To substantiate the result of cronbach alpha and item itemtotal correlation of the ASES-FJHS Final Form, the researcher used Split-half method specifically Guttman and SpearmanBrown Coefficient to measure coefficient of internal consistency and coefficient of equivalence. Results showed that the Cronbach alpha of the two halves are 0.905 and 0.940 , respectively, both halves have high level of equivalence coefficient. These results were further substantiated by Spearman-Brown coefficient with 0.865 index and Guttman coefficient of 0.861 (see Table A5 in Appendix).

\section{Validation of the ASES-FJHS Final Form}

Academic Self-efficacy Scale was validated among 450 secondary high school students using convergent and concurrent validity. Table 2 presents the Convergent Validity correlation between Academic Self-efficacy Scale (ASES-FJHS) for Filipino Junior High School Students Final Form and Children Self-Efficacy Scale (CSET). In the convergent validity, the Children's Self-Efficacy Scale (Bandura, 2006) was used. The CSES measures academic efficacy of students with norming on secondary high schools (until grade 10). In addition, concurrent validity was established by correlating the GWA of the students to their scores on ASES Final Form at the same time.

\section{Convergent Validity of ASES-FJHS Final Form}

To examine if the newly developed ASES for Filipino K to 12 junior high school students Grade 7 to 10 is valid both in nature and content, it was tested using convergent validity to a standardized measures of Self-Efficacy, i.e., Children's Self-Efficacy Scale or CSES (Bandura, 2006). The Children's Self-Efficacy Scale created by Bandura (2006) is a specific measure of self-efficacy in the academic context. Thus, it is appropriate to measure the convergence of ASES Final Form with Bandura's CSES. Results showed that the correlation between ASES Final Form and Bandura's Children Self-Efficacy Scale has significant moderate relationship $\left(r=0.498^{*} ; p<0.05\right)$.

\section{Concurrent Validity of ASES-FJHS Final Form}

Another validation measure used in the study was concurrent validity. In the case of ASES Final Form, it was paired with the GWA of junior high school students to measure the predictive
TABLE 2 | Convergent Validity correlation between Academic Self-efficacy Scale (ASES) Final Form and CSES.

\begin{tabular}{lcc}
\hline & $\mathbf{1}$ & $\mathbf{2}$ \\
\hline 1. ASES final form & - & $0.498^{*}$ \\
2. Children's Self-efficacy Scale & & - \\
\hline${ }^{*} p<0.05$. & &
\end{tabular}

TABLE 3 | Correlation between Academic Self-efficacy Scale (ASES) Final Form and High School Students' GWA.

\begin{tabular}{lcc}
\hline & $\mathbf{1}$ & $\mathbf{2}$ \\
\hline $\begin{array}{l}\text { 1. Grade Weighted Average } \\
\text { 2. ASES Final Form }\end{array}$ & - & $0.518^{* *}$ \\
${ }^{* *} p<0.01$ & & - \\
\hline
\end{tabular}

${ }^{* *} p<0.01$

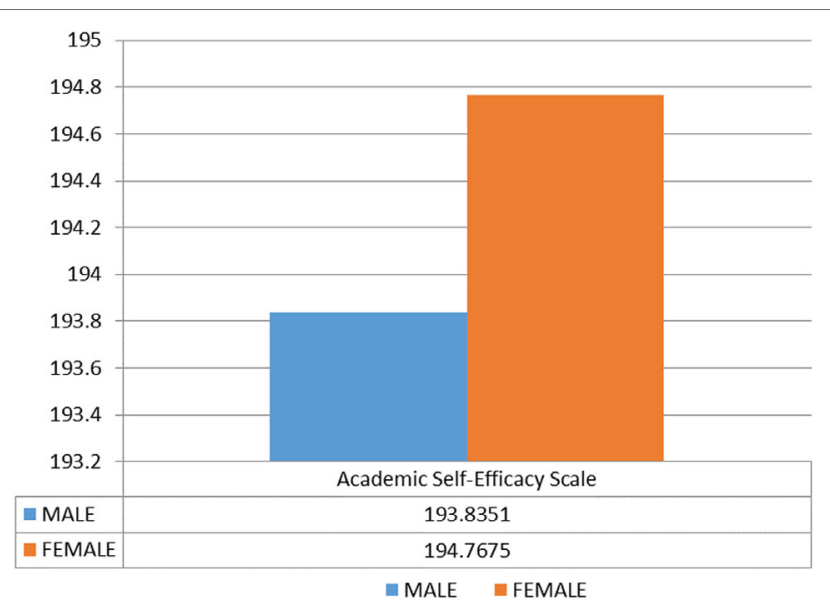

FIGURE 1 | Male and Female Junior High Students' Raw Score on Academic Self-efficacy Scale.

index of ASES in terms of their academic performance. Results showed that the ASES Final Form has high significant moderate relationship with the grades of high school students $\left(r=0.518^{* *}\right.$; $p<0.01)$. Table 3 presents the Correlation between Academic Self-efficacy Scale (ASES-FJHS) Final Form and High School Students' Grade Weighted Average (GWA).

\section{Gender Difference in Terms of K to 12 Junior High School Students' Level of Academic Self-Efficacy}

The researcher also explored the gender difference per ASES domains, i.e., PC, Competence, Persistence, and SRL. Figures 1 and 2 presents the raw score of Filipino male and female junior high school students on ASES and its domains. Results showed that the female has slightly higher score than male. Though the raw scores indicate slight difference, results of test of difference on the other hand showed that there is no significant difference between male and female in their Academic Self-Efficacy $(t=-1.021 ; p>0.01)$. On the other hand, the domain level of the ASES showed different outcome. Results indicated that there 


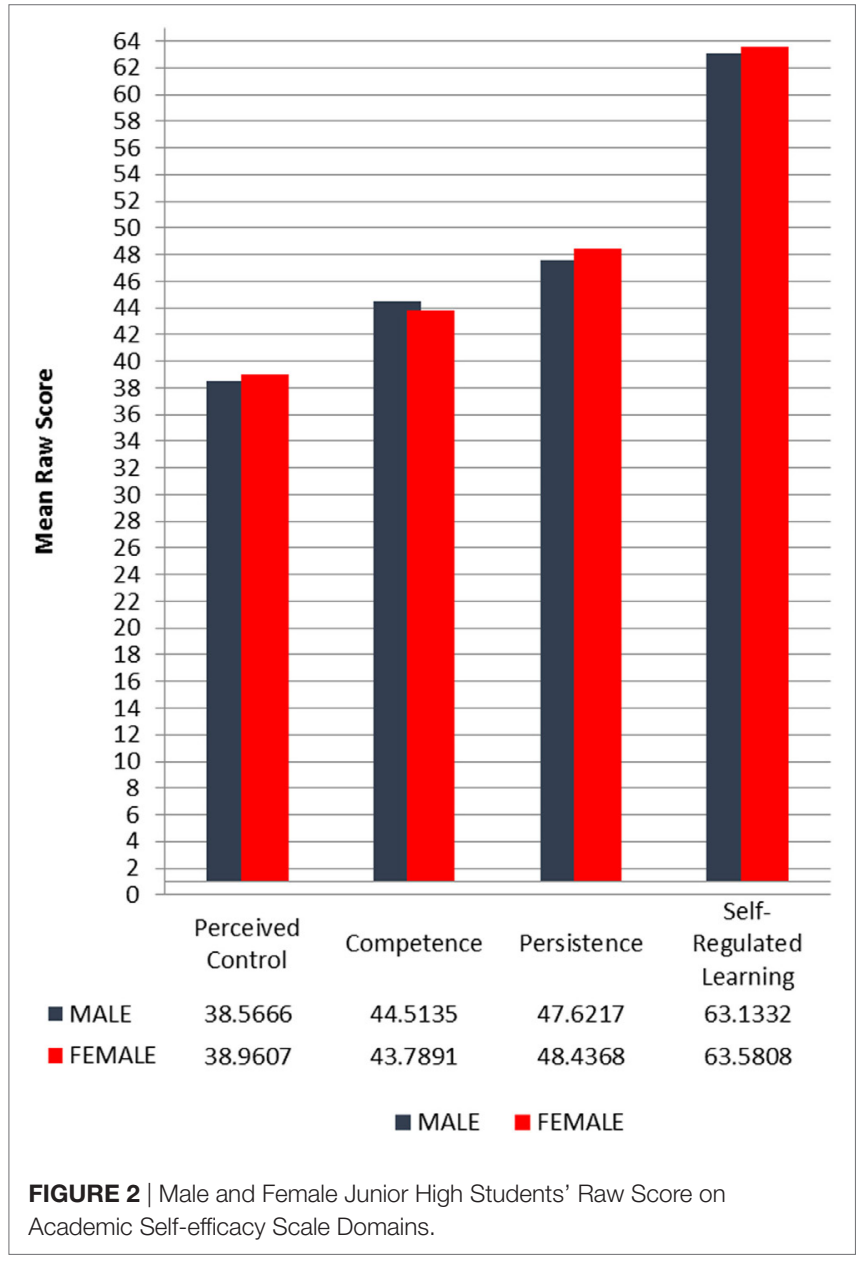

are significant differences on PC, Competence, and Persistence domains score among female and male junior high school students. Results showed that on PC, female junior high school students have higher raw score than male junior high school students. These results were further validated by independent sample $t$-test. The analysis revealed that there is significant difference between female and male junior high students $(t=2.435$; $p<0.015)$ on the PC domain. In addition, female junior high school students have higher raw score than male on the Persistence domain. There is significant difference $(t=-3.513$; $p<0.00$ ) between the raw scores, with the females obtaining the higher belief on their persistence. On the contrary, male junior high school students have higher raw score on Competence than female junior high school students. These results were further verified through $t$-test. The analysis showed that there is significant difference between male and female in their Competence level $(t=3.236 ; p<0.01)$.

\section{DISCUSSION}

This part includes the implication and integration of the data and findings of other related studies from the development, reliability, and validity measures of the study. Using CVR, the items were analyzed. Lawshe's CVR serves as a method of deriving for the content validity index of the items (Wilson et al., 2012; Cohen et al., 2013). For the implementation of CVR among four validators, each item must reach a CVR equal to or more than 0.75 to be included in the initial form (Ayre and Scally, 2013). Overall CVI of ASES in its initial form is 0.87. Ayre and Scally (2013) suggest that when the scale has a CVI of 0.75 and above, the scale is content valid. This is consistent with the findings of the study. Further analyses such as intra-class correlation (ICC) supported the result. Intra-class correlation discusses the consistency or agreement of raters or judges on the items of the scale/ test (Landers, 2015). Result showed that $95.3 \%$ of the variance in the mean of these raters is "real." It means that there is high agreement between the validators of the scale. This implies that the initial items of the ASES-FJHS were valid based on these two analyses. On the other hand, UL-LL or the extreme method is utilized for item analysis. The UL-LL method is described as one of the approaches in item analysis for identification of item discrimination index (Cohen et al., 2013; Erford, 2013). The discrimination index of the whole ASES-FJHS is 0.45 . In addition, the difficulty index of the scale is 0.73 . Both indices indicate that the ASES for Filipino junior high school students has the capacity to discriminate or distinguish between high performers from the low performers in terms of the students' perceived belief about their academic performance. The analysis is supported by Aiken (2000) which stated that item discrimination is a measure of how effectively an item discriminates between examinees who score high on the test as a whole (or on some other criterion variable) from those who score low. ASES-FJHS can differentiate with low and high Academic efficacy beliefs. In terms of reliability analysis, Cronbach alpha and Item-Total Correlation were also used. Splithalf method was also utilized for additional analysis. Based from the different reliability measures specifically Cronbach alpha and Item-Total Correlation, a total of 142 items were eliminated from the pool of items. This is supported by the studies of Kline (1993) and Rust and Golombok (1992) which suggest that item to total score correlation and Cronbach alpha are methods for item analysis. These two analyses are also ways of finding if the item is really discriminating. Low correlation coefficient means that the item has a weak relation to the concept of the test being develop. Erford (2013) and Tavakol and Dennick (2011) used correlation coefficient of 0.2 below $p$ value for the elimination or revision of the items. In other manifestation, the item that has low or weak correlation coefficient is not discriminating.

On the other hand, Cronbach alpha is a measure of reliability, much more of internal consistency or a measure of interrelatedness of the items in the test (Tavakol and Dennick, 2011). Thus, these reliability measures were used to eliminate items that are non-functioning.

\section{Development of the Final Form of the ASES for Filipino Junior High School Students Through Principal Component Analysis}

Principal Component Analysis is utilized since there are predetermined factors namely PC, Persistence (P), Competence (C), and SRL. Before conducting the factor analysis, assumptions 
were verified such as the correlation matrix, $\mathrm{KMO}$, and Bartlett's test of sphericity. These methods are consistent with the studies which were conducted by other self-efficacy developers (Singh and Bussey, 2009; Can, 2010). Results showed that the correlation coefficients were above 0.30 and the KMO index of sampling adequacy is 0.97 . In addition, Bartlett's test of sphericity showed statistically significant result. Thus, the assumptions were met before conducting the factor analysis. After verifying the assumptions, factor structure was analyzed using principal component and varimax rotation solutions involving four factors. Items that failed to load at 0.30 value or higher were eliminated. This basal value was also used by other Self-efficacy scale developer like Can (2010) and Singh and Bussey (2009) in including an item in the factor loading and factor structure of a specific self-efficacy domain. On the case of ASES-FJHS the four-factor iteration was consistent to the domains of the scale. This analysis contributed to the validity measures of the scale. Factor analysis specifically Principal Factor Component is mathematical procedure for analyzing a matrix of correlations among measurements to determine what factors (constructs) are sufficient to explain the correlations. Its major purpose is to reduce the number of variables in a group of measures by taking into account the overlap (correlations) among them (Cohen et al., 2013). This analysis further explains the consistency of items and its relation to domains and overall construct of the scale.

\section{Reliability of the ASES in its Final Form}

Reliability measures of the ASES-FJHS manifest high coefficients. The result of cronbach alpha of the ASES final form is 0.95 on its standardized items. Tavakol and Dennick (2011), DeVellis (2003), and Bland and Altman (1997) described that the acceptable values for cronbach alpha are ranging from 0.70 to 0.95 . Thus, the elimination of the redundant items made the Final Form more reliable and internally consistent. In relation to the development of Self-efficacy scale, Bandura (2006) described that reliability, in the form of internal consistency through Cronbach alpha, places an upper limit on the maximum possible correlation that can be obtained between variables. Results of Cronbach alpha imply that the individual domains of ASES are highly reliable in terms of internal consistency. The measure of internal consistency or the interrelatedness of the items in the test (Tavakol and Dennick, 2011). Split-half method specifically Guttman and SpearmanBrown Coefficient were further used to measure coefficient of internal consistency and coefficient of equivalence. Results showed very high correlation between halves. Spearman-Brown coefficient and Guttman coefficient also obtained a very high coefficient. Results suggest that the ASES-FJHS has high internal consistency and internal equivalence. According to Cohen et al. (2013) and Erford (2013) that the measures of split-half reliabilities assumes the good characteristics of the test maintaining homogeneity and unitary of each items.

\section{Validation of the ASES Final Form Convergent Validity of ASES Final Form}

Results showed that the correlation between ASES Final Form and Bandura's Children Self-Efficacy Scale has significant moderate relationship. This implies that the ASES Final Form has moderate convergent validity with a standardized academic self-efficacy measure like the CSES. However, it is good to elaborate that the $p$ value is not that high. This indicates that the newly developed ASES is different from the established standardize measure of self-efficacy like the CSES, though it is also clear that the correlation between the two scales are significant. In addition, convergent validity indicates that the test measures the same construct as what the other tests purport to measure (Cohen et al., 2013; Feist et al., 2013). In relation to ASES, it has significant convergence with the existing standardized tests of Self-Efficacy contextualized in the academic setting. On the other hand, it also showed a different measure of academic selfefficacy both in content and nature as indicated by the results of the $p$ value.

\section{Concurrent Validity of ASES Final Form}

Another validation measure used in the study was concurrent validity. Concurrent validity measures the relationship between the test scores and the criterion measure obtained at the same time. In other words, if test scores are obtained at about the same time as the criterion measures are obtained, measures of the relationship between the test scores and the criterion provide evidence of concurrent validity (Cohen et al., 2013; Feist et al., 2013). In the case of ASES Final Form, it was paired with the GWA of junior high school students to measure the predictive measure of ASES in terms of their academic performance. Results showed that the ASES Final Form has high significant moderate relationship with the grades of high school students. This manifested that as the Academic Self-Efficacy of Filipino junior high school students increases, their GWA also increases. This result is consistent with the recent findings of Hermita and Thamrin (2015), Jansen et al. (2015), Brown et al. (2013), Komarraju and Nadler (2013), and Pastorelli et al. (2001) that self-efficacy is a good measure of student's academic performance. The result of concurrent validation is consistent with the findings from other researches.

\section{Gender Difference on Level of Academic Self-Efficacy}

Results of test of difference on the other hand showed that there is no significant difference between male and female in their overall Academic Self-Efficacy. The findings of the study are consistent with the results of recent studies exploring gender difference on Academic Self-Efficacy. Schnell et al. (2015) and Dullas (2012) found that there is no gender difference on the level of self-efficacy among adolescent high school students. On the other hand, the domain level of the ASES showed different outcome. Results indicated that there are significant differences on PC, Competence, and Persistence domains score among female and male junior high school students. These findings are also consistent with the meta-analyses of Stetsenko et al. (2002). They found out that when girls have higher grades than boys, it also follows that they have higher beliefs than boys in several facets of achievement potentials which includes effort or persistence in the academics. The results are also consistent with the findings of Vantieghem et al. (2014) that functions of traits, attitudes and 
behavior including persistence, and femininity are more conducive to educational achievement.

On the contrary, male junior high school students have higher raw score on Competence than female junior high school students. This result is consistent with the findings of other researches which states that female high school students have lower perception of their competence and lower performance expectations than male high school students (Stipek, 1992; Stetsenko et al., 2002). In addition, the results of the study were supported by Mohammadyari (2012), which states that male students had higher competence as a function of social expectation and consideration and that to be capable was a male trait in relation to academic achievement.

\section{Application of Bandura's Social Cognitive Theory}

Bandura's Social Cognitive theory emphasizes the relevance and interactions of environment, person's variable and behaviors both in personality and learning. The triadic causation model emphasizes that human functioning is the product of the interaction between (B) behavior, (P) person's variable, and (E) environment. Reciprocal means not similar or opposite rather than expressing the triadic interaction of the three variables. Person's variable includes cognitive factors, such as beliefs, memory, planning, and judging. By cognitive functions, people have the capacity to select or choose to attend from the environment or what to give value for example (Bandura, 2012; Feist et al., 2013). Using Bandura's Theory, ASES-FJHS measures the perceived belief of Filipino Junior High School students on their academic self-efficacy. This is also connected with their behavior (i.e., Graded Weighted Average) and their environment (i.e. academic subjects in school setting). Thus, the relevance and interactions of environment, person's variable, and behaviors primarily on their academic learning captured by the scale.

\section{Conclusion}

Based on the findings revealed in the study, the researcher concluded that the newly developed ASES Filipino Junior High School students (ASES-FJHS) is a reliable and valid measure of academic self-efficacy. This is based from the different reliability and validity analyses applied. However, further validity measures must also be applied using national and Asian samples.

\section{Recommendations and Future Trend}

The ASES-FJHS is useful for assessing the efficacy belief of Filipino high school students. However, there are recommendations needed to accomplish and as well as the future trend of the newly developed scale. The researcher recommends to validate the newly developed ASES-FJHS with the national norming since the basis for the norming of ASES is only confined on private and public schools in one region in the Philippines. Moreover, it is also suggested to further validate by administering the ASES to diverse characteristics of students (example in terms of ethnicity) and of course in Asian countries were the context of students were very much different with the students in Western countries. In addition it is also suggested to use test-retest (over a relative short time) as form of reliability measure and other forms of reliability and validation techniques for further investigation.

For policy makers, the researcher recommends the use of the findings of this study as their reference. This may give significant information on the level of Academic Self-Efficacy Filipino Junior High School Students. Perhaps, the scale may also use to create a possible program that may enhance students with low level of Academic Self-efficacy specifically on the four identified domains (example is the Competence Enhancement Program or Persistence Enhancement Program). For government institutions such as DepEd (Department of Education), with Filipino Junior High School Students as the main clientele, the findings of this study are recommended as reference in their programs and may be used as a screening procedure (pretest) or evaluation procedure (posttest) among the academic beliefs of Junior high school students. This is a good future trend since most of the programs are intended for academic/subject intervention rather than specific belief such as academic self-efficacy. It is also suggested to integrate the four domains of ASES namely: PC, Competence, Persistence, and SRL to be part of the values integration of the Department of Education curriculum in the Philippines.

\section{ETHICS STATEMENT}

This study was carried out in accordance with the recommendations of "name of guidelines, name of committee" with written informed consent from all subjects. All subjects gave written informed consent in accordance with the Declaration of Helsinki. The protocol was approved by the University of Santo Tomas, Graduate School Ethics Review Committee.

\section{AUTHOR CONTRIBUTIONS}

The author confirms being the sole contributor of this work and approved it for publication.

\section{ACKNOWLEDGMENTS}

The author wants to express his deepest gratitude and admiration to the people who supported and helped him in one way or another to fulfill this study: Dr. Joy Tungol, his adviser and Prof. Dennis De Vera for constructive criticisms.

\section{FUNDING}

This research was carried out with a grant from the Commission on Higher Education (CHED) through Faculty Development Program Phase II (CHED FDP-II).

\section{SUPPLEMENTARY MATERIAL}

The Supplementary Material for this article can be found online at https://www.frontiersin.org/articles/10.3389/feduc.2018.00019/ full\#supplementary-material. 


\section{REFERENCES}

Aiken, L. R. (2000). Psychological Testing and Assessment. Boston: Allyn and Bacon Inc.

Anderman, E. M., Urdan, T., and Roeser, R. (2005). “The patterns of adaptive learning survey," in What Do Children Need to Flourish? Conceptualizing and Measuring Indicators of Positive Development, eds K. A. Moore and L. H. Lippman (New York, NY: Springer Science), 223-235.

Ayre, C., and Scally, A. J. (2013). Critical values for Lawshe's content validity ratio: revisiting the original methods of calculation. Meas. Eval. Couns. Dev. 47, 79-86. doi:10.1177/0748175613513808

Bandura, A. (1994). "Self-efficacy," in Encyclopedia of Human Behavior, Vol. 14, ed. V. S. Ramachaundran (New York: Academic Press), 71-81.

Bandura, A. (1997). Self-Efficacy: The Exercise of Control. New York, NY: W. H. Freeman.

Bandura, A. (2006). "Guide for constructing self-efficacy scales," in Self-Efficacy Beliefs of Adolescents, Vol. 5. eds. F. Pajares and T. Urdan (Greenwich, CT: Information Age Publishing), 307-337.

Bandura, A. (2012). "Self-efficacy mechanisms in physiological activation and health-promoting behaviour," in Neurobiology of Learning, Emotion and Affection, ed. J. Madden IV (New York: Raven), 229-270.

Bland, J., and Altman, D. (1997). Statistics notes: Cronbach's alpha. BMJ 314, 275. doi:10.1136/bmj.314.7080.572

Boekaerts, M., and Cascallar, E. (2006). How far have we moved toward the integration of theory and practice in self-regulation? Educ. Psychol. Rev. 18, 199-210. doi:10.1007/s10648-006-9013-4

Bouffard, T., Bouchard, M., Goulet, G., Denoncourt, I., and Couture, N. (2005). Influence of achievement goals and self-efficacy on students' self-regulation and performance. Int. J. Psychol. 40, 373-384. doi:10.1080/00207590444 000302

Brown, L. J., Malouff, J. M., and Schutte, N. S. (2013). Self-Efficacy Theory. Armidale, NSW: University of New England.

Can, G. (2010). Development of elementary school counselor self-efficacy scale. Proc. Soc. Behav. Sci. 9, 1629-1633. doi:10.1016/j.sbspro.2010.12.300

Cazan, A. M. (2012). Self regulated learning strategies - predictors of academic adjustment. Proc. Soc. Behav. Sci. 33, 104-108. doi:10.1016/j.sbspro.2012. 01.092

Chen, J. A., and Usher, E. L. (2013). Profiles of the sources of science self-efficacy. Learn. Individ. Differ. 24, 11-21. doi:10.1016/j.lindif.2012.11.002

Cohen, R. J., Swedlik, M. E., and Sturman, E. D. (2013). Psychological Testing and Assessment: An Introduction to Tests and Measurement, 8th Edn. New York: McGraw-Hill Inc.

Coutinho, S. (2008). Self-efficacy, metacognition, and performance. N. Am. J. Psychol. 10, 165-172

Department of Education. (2012). Guidelines on the Assessment and Rating of Learning Outcomes under the $K$ to 12 Basic Education Curriculum. Manila, Philippines: Department of Education (DepEd. Order No. 73, S. 2012).

DeVellis, R. (2003). Scale Development: Theory and Applications: Theory and Application. Thousand Oaks, CA: SAGE.

Diseth, A. (2011). Self-efficacy, goal orientation and learning strategies as mediators between preceding and subsequent academic achievement. Learn. Individ. Differ. 21, 191-195. doi:10.1016/j.lindif.2011.01.003

Do-Hong, K., Chuang, W., Hyun, S. A., and Mimi, B. (2015). English language learners' self-efficacy profiles and relationship with self-regulated learning strategies. Learn. Individ. Differ. 38, 136-142. doi:10.1016/j.lindif.2015.01.016

Dullas, A. R. (2012). Self-Efficacy and Academic Performance of Filipino Science High School Students on Mathematics and English Subjects. Social Science Research Network. Available at: http://papers.ssrn.com/sol3/topten/topTenResults.cfm?groupingId=1314043\&netorjrnl=jrnl (Accessed: June 08, 2016).

Erford, B. T. (2013). Assessment for Counselors. USA: Brooks/Cole CENCAGE Learning.

Feist, J., Feist, G. J., and Roberts, T. (2013). Theories of Personality, 8th Edn. New York: McGraw-Hill Inc.

Harter, S. (1985). The Self-Perception Profile for Children: Revision of the Perceived Competence Scale for Children. Denver, CO: University of Denver.

Hermita, M., and Thamrin, W. P. (2015). Metacognition toward academic self-efficacy among Indonesian private university scholarship students. Proc. Soc. Behav. Sci. 171, 1075-1080. doi:10.1016/j.sbspro.2015.01.268
Huang, C. (2013). Gender differences in academic self-efficacy: a meta-analysis. Eur. J. Psychol. Educ. 28, 1-35. doi:10.1007/s10212-011-0097-y

Jansen, M., Scherer, R., and Schroeders, U. (2015). Students' self-concept and self-efficacy in the sciences: differential relations to antecedents and educational outcomes. Contemp. Educ. Psychol. 41, 13-24. doi:10.1016/j.cedpsych.2014. 11.002

Jinks, J., and Morgan, V. (1999). Morgan-Jinks Student Efficacy Scale (MJSES) children's perceived academic self-efficacy: an inventory scale. Clear. House 72, 224-230. doi:10.1080/00098659909599398

Khezriazara, H., Lavasania, M. G., Malahmadia, E., and Amania, J. (2010). The role of self- efficacy, task value, and achievement goals in predicting learning approaches and mathematics achievement. Proc. Soc. Behav. Sci. 5, 942-947. doi:10.1016/j.sbspro.2010.07.214

Kleitman, S., and Gibson, J. (2011). Metacognitive beliefs, self-confidence and primary learning environment of sixth grade students. Learn. Individ. Differ. 21, 728-735. doi:10.1016/j.lindif.2011.08.003

Kline, P. (1993). The Handbook of Psychological Testing. New York: Rouledge Publication.

Klomegah, R. Y. (2007). Predictors of academic performance of university students: an application of the goal efficacy model. Coll. Stud. J. 41, 407-415.

Komarraju, M., and Nadler, D. (2013). Self-efficacy and academic achievement: why do implicit beliefs, goals, and effort regulation matter? Learn. Individ. Differ. 25, 67-72. doi:10.1016/j.lindif.2013.01.005

Landers, R. N. (2015). Computing intraclass correlations (ICC) as estimates of interrater reliability in SPSS. Winnower 2, e143518.81744. doi:10.15200/ winn.143518.81744

Lent, R. W. (2005). "A social cognitive view of career development and counseling," in Career Development and Counseling: Putting Theory and Research to Work, eds S. D. Brown and R. T. Lent (Hoboken, NJ: Wiley), 101-127.

Linnenbrink, E., and Pintrich, P. (2003). The role of self-efficacy beliefs in student engagement and learning in the classroom. Read. Writ. Q. 19, 119-137. doi:10.1080/10573560308223

Midgley, C., Maehr, M. L., Hruda, L. Z., Anderman, E., Anderman, L., Freeman, K. E., et al. (2000). Manual for the Patterns of Adaptive Learning Scales. Michigan: University of Michigan. Available at: http://www.umich.edu/ pals/PALS\%20 2000_V12Word97.pdf (Accessed: June 18, 2016).

Mohammadyari, G. (2012). Comparative study of relationship between general perceived self-efficacy and test anxiety with academic achievement of male and female students. Proc. Soc. Behav. Sci. 69, 2119-2123. doi:10.1016/j. sbspro.2012.12.175

Nelson, B., and Ketelhut, D. (2008). Exploring embedded guidance and self-efficacy in educational multi-user virtual environments. Int. J. Comput. Support. Collab. Learn. 3, 413-427. doi:10.1007/s11412-008-9049-1

Pajares, F., and Miller, D. M. (1994). Role of self-efficacy and self-concept belief in mathematical solving: a path analysis. J. Educ. Psychol. 2, 193-203. doi:10.1037/0022-0663.86.2.193

Pastorelli, C., Caprara, G. V., Barbaranelli, C., Rola, J., Rozsa, S., and Bandura, A. (2001). The structure of children's perceived self-efficacy: a cross-national study. Eur. J. Psychol. Assess. 17, 87-97. doi:10.1027//1015-5759.17.2.87

Pintrich, P. R., and De Groot, E. V. (1990). Motivational and self-regulated learning components of classroom academic performance. J. Educ. Psychol. 82, 33-40. doi:10.1037/0022-0663.82.1.33

Rust, J., and Golombok, S. (1992). Modern Psychometrics: The Science of Psychological Assessment. New York: Rouledge Publication.

Salmeron, P. H., Gutierrez, B. C., Fernandez, C. A., and Salmeron, V. P. (2010). Self-Regulated Learning, Self-Efficacy Beliefs and Performance during the Late Childhood. RELIEVE. Vol. 16, n. 2, art.4, 1-18. Available at: http://www.uv.es/ RELIEVE/v16n2/RELIEVEv16n2_4eng.htm (Accessed: June 24, 2016).

Schnell, K., Ringeisen, T., Raufelder, D., and Rohrmann, S. (2015). The impact of adolescents' self-efficacy and self-regulated goal attainment processes on school performance-do gender and test anxiety matter? Learn. Indiv. Diff. 38, 90-98. doi:10.1016/j.lindif.2014.12.008

Schunk, D. H. (1995). "Self-efficacy and education and instruction," in Self-Efficacy, Adaptation, and Adjustment: Theory, Research, and Application, ed. E. Maddux (New York: Plenum), 281-303.

Schunk, D. H., and Pajares, F. (2002). "The development of academic self-efficacy," in Development of Achievement Motivation, eds A. Wigfield and J. Eccles (San Diego: Academic Press). 
Schwarzer, R. (1998). Optimism, goals, and threats: how to conceptualize self-regulatory processes in the adoption and maintenance of health behaviors. Psychol. Health 13, 759-766. doi:10.1080/08870449808407430

Schwarzer, R. (2001). Social-cognitive factors in changing health-related behavior. Curr. Dir. Psychol. Sci. 10, 47-51. doi:10.1111/1467-8721.00112

Singh, P., and Bussey, K. (2009). The development of a Peer Aggression Coping Self-efficacy Scale for adolescents. Br. J. Dev. Psychol. 27, 971-992. doi:10.1348/ $026151008 X 398980$

Stetsenko, A., Little, T. D., Gordeeva, T., Grasshof, M., and Oettingen, G. (2002). "Gender effects in children's beliefs about school performance: a cross-cultural study," in Human Development in Multicultural Contexts: A Book of readings, ed. M. A. Paludi (Upper Saddle River, NJ: Pearson/Merrill Prentice Hall), 107-111.

Stipek, D. J. (1992). “The child at school," in Developmental Psychology: An Advanced Textbook, eds M. Bornstein and M. E. Lamb (Hillsdale, NJ: Erlbaum), 579-625.

Tavakol, M., and Dennick, R. (2011). Making sense of Cronbach's alpha. Int. J. Med. Educ. 2, 53-55. doi:10.5116/ijme.4dfb.8dfd

Usher, E. L., and Pajares, F. (2009). Sources of self-efficacy in mathematics: a validation study. Contem. Educ. Psychol. 34, 89-101. doi:10.1016/j. cedpsych.2008.09.002

Vantieghem, W., Vermeersch, H., and Houtte, M. V. (2014). Transcending the gender dichotomy in educational gender gap research: the association between gender identity and academic self-efficacy. J. Contem. Educ. Psychol. 39, 369-378. doi:10.1016/j.cedpsych.2014.10.001

Wigfield, A., and Eccles, I. S. (2000). Expectancy-value theory of achievement motivation. Contemp. Educ. Psychol. 25, 68. doi:10.1006/ceps.1999.1015
Wilson, F. R., Pan, W., and Schumsky, D. A. (2012). Recalculation of the critical values for Lawshe's content validity ratio. Meas. Eval. Couns. Dev. 45, 197-210. doi:10.1177/0748175612440286

Wood, S., and Wood, E. (1996). The World of Psychology, 2nd Edn. USA: Allyn and Bacon.

Zimmerman, B. J. (2008). Investigation self-regulation and motivation: historical background, methodological developments, and future prospects. Am. Educ. Res. J. 45, 166-183. doi:10.3102/0002831207312909

Zimmerman, B. J., and Cleary, T. J. (2006). “Adolescents' development of personal agency," in The Role of Self-Efficacy Belief and Self-Regulatory Skill (Greenwich, CT: Information Age Publishing), 45. Available at: http://www.des.emory.edu/ mfp/ZimmermanClearyAdoEd5.pdf (Accessed: June 24, 2016).

Zimmerman, B. J., and Schunk, A. (2008). "Motivation: An essential dimension of self regulated learning," in Motivation and Self-Regulated Learning: Theory, Research, and Applications, eds D. H. Schunk and B. J. Zimmerman (Nueva York: Erlbaum), 1-30.

Conflict of Interest Statement: The author declares that the research was conducted in the absence of any commercial or financial relationships that could be construed as a potential conflict of interest.

Copyright (c) 2018 Dullas. This is an open-access article distributed under the terms of the Creative Commons Attribution License (CC BY). The use, distribution or reproduction in other forums is permitted, provided the original author(s) and the copyright owner are credited and that the original publication in this journal is cited, in accordance with accepted academic practice. No use, distribution or reproduction is permitted which does not comply with these terms. 


\section{APPENDIX}

TABLE A1 | Academic Self-efficacy Scale for Filipino Junior High School Students Final Form.

\section{Perceived control items}

1. I will succeed because I can improved my study habit.

2. I will be able to finish Junior high school because I am smart enough to do so.

3. When I am called in recitations, I give the correct answer because I paid attention.

4. Passing a subject depends on how well I perform.

5. The future depends on what I do now.

6. My teachers give me high marks because I deserve it.

7. Because I develop good study habits, I learn more.

8. I can successfully control the outcome of my performance tasks such as group presentations, oral works,

multimedia presentations, and research projects.

9. My teachers see me as a good student.

10. I believe that I can pass English subject because I have the ability to do so.

11. I believe that I can pass Math subject because I have the ability to do so.

12. I can successfully control the outcome written works in my academics such as quizzes, unit, or long test.

\section{Competence items}

13. In whatever I do, I strive to attain excellence.

14. I do things creatively and it helps me to get a good mark.

15. I can perform very well in any field I get into.

16. During exams, I do not feel anxious because I know I can pass the test with high marks.

17. On the spot recitations does not make me nervous because I can answer them well.

18. My teachers see me as one of the best students in class.

19. I am convinced that I can master the concepts and topics taught in my class.

20. Compared with my classmates, I think that I am a better academic performer.

21. I can do excellent job in my subjects.

22. I do not worry about the assigned task to me in class.

23. I can get good grades in my written works such as quizzes, unit, or long test.

24. I can perform my tasks in my academics such as group presentation, oral work, multimedia presentations, and research projects.

25. I can pass my quarterly assessment such as periodical test.

26. I am competent to pass Science subject.

27. I am competent to pass Filipino subject.

\section{Persistence items}

28. Despite discouragement from peers, I still continue to study hard.

29. In spite of pressures in school, I continue to maintain my good grades.

30. I manage to pull through even when others think there is no hope in passing a subject.

31. When I'm having a hard time understanding the lesson, I never stop trying.

32. Regardless of obstacles, I keep moving toward my goal.

33. If I will not give up I can figure out difficult homework.

34. If I try really hard, I can get through even the most difficult subject.

35. I know how to help myself and that is persistently working hard.

36. I persistently solve problems with regards to my academic subjects.

37. I consistently figure out how to do the most difficult class works.

38. If I don't give up, I can do almost all hard tasks in school.

39. Even if there are many obstacles, I can learn it.

40. I am persistent to pass Araling Panlipunan (Social Studies) subject.

41. I work hard despite of difficulties to get good grades in written works in my academics such as quizzes, unit, or long tests.

42. Despite obstacles, I am able to accomplish my performance tasks in my academics such as group presentation,

oral work, multimedia presentations, and research projects.

\section{Self-regulated learning items}

43. I can adjust whenever there are hard activities in class.

44. I can study on my own.

45. Whenever there are suggestions with regards to my negative study habits, I welcome it to change.

46. I can monitor my learning development.

47. I can submit my requirements before the deadlines.

48. I organize my school works.

49. I plan my school activities.

50. I can remember the presented discussions in class.

51. I can apply my lessons in textbooks. 
TABLE A1 | Continued

\section{Self-regulated learning items}

52. I can focus to study.

53. I arrange my study room to learn without distractions.

54. I can motivate myself to do school works and assignments.

55. I can motivate myself to learn.

56. I am motivated to pass Edukasyon sa Pagpapakatao (Values Education) subject.

57. I am motivated to pass Edukasyong Pantahanan at Pangkabuhayan (Technology and Livelihood Education) subject.

58. I am motivated to pass MAPEH (Music, Arts, Physical Education and Health) subject.

59. When I commit mistakes, I am willing to adjust my behavior.

60. I believe I perform at my best in written works in my academics such as quizzes, unit, or long test.

61. I organize and plan proficiently to succeed in my performance tasks in my academics such as group presentations,

oral work, multimedia presentations, and research projects.

62. I am motivated to excel in my quarterly assessment in my academics such as periodical exams.

$S A$, strongly agree; $A$, agree; $D$, disagree; $S D$, strongly disagree.

TABLE A2 | Intraclass Correlation Coefficient (ICC) of the four judges on ASES-FJHS.

\section{Intraclass correlation coefficient}

\begin{tabular}{|c|c|c|c|c|c|c|c|}
\hline & \multirow[t]{2}{*}{ Intraclass correlation ${ }^{\mathrm{b}}$} & \multicolumn{2}{|c|}{ 95\% Confidence interval } & \multicolumn{4}{|c|}{$F$ test with true value 0} \\
\hline & & Lower bound & Upper bound & Value & df1 & df2 & Sig \\
\hline Single Measures & $0.078^{a}$ & 0.025 & 0.544 & 76.507 & 3 & 717 & 0.000 \\
\hline Average Measures & 0.953 & 0.862 & 0.997 & 76.507 & 3 & 717 & 0.000 \\
\hline
\end{tabular}

Two-way random effects model where both people effects and measures effects are random.

aThe estimator is the same, whether the interaction effect is present or not.

${ }^{\circ}$ Type A intraclass correlation coefficients using an absolute agreement definition.

TABLE A3 | Factor structure and factor loadings of ASES Final Form.

\begin{tabular}{|c|c|c|c|c|}
\hline \multicolumn{5}{|c|}{ Component } \\
\hline & 1 & 2 & 3 & 4 \\
\hline PC1 & 0.245 & 0.114 & 0.627 & 0.129 \\
\hline PC2 & 0.194 & 0.183 & 0.521 & 0.080 \\
\hline PC3 & 0.224 & 0.327 & 0.410 & 0.028 \\
\hline PC4 & 0.221 & 0.038 & 0.624 & 0.136 \\
\hline PC5 & 0.188 & 0.035 & 0.547 & 0.111 \\
\hline PC6 & 0.166 & 0.232 & 0.572 & 0.026 \\
\hline PC7 & 0.219 & 0.132 & 0.626 & 0.102 \\
\hline PC8 & 0.173 & 0.091 & 0.510 & 0.199 \\
\hline PC9 & 0.024 & -0.054 & 0.064 & 0.096 \\
\hline PC10 & 0.091 & 0.414 & 0.099 & -0.105 \\
\hline PC11 & 0.114 & 0.000 & 0.015 & -0.255 \\
\hline PC12 & 0.202 & 0.181 & 0.497 & 0.111 \\
\hline PC13 & 0.054 & 0.135 & 0.095 & 0.093 \\
\hline PC14 & 0.114 & 0.463 & 0.168 & -0.095 \\
\hline PC15 & 0.210 & 0.039 & 0.558 & 0.202 \\
\hline PC16 & 0.184 & 0.273 & 0.447 & 0.037 \\
\hline PC17 & 0.156 & 0.396 & 0.327 & 0.037 \\
\hline C18 & 0.168 & 0.301 & 0.260 & 0.213 \\
\hline C19 & 0.290 & 0.341 & 0.377 & 0.191 \\
\hline C20 & 0.233 & 0.510 & 0.201 & 0.125 \\
\hline $\mathrm{C} 21$ & 0.195 & 0.297 & 0.228 & 0.168 \\
\hline C22 & 0.167 & 0.600 & 0.067 & 0.108 \\
\hline C23 & 0.119 & 0.553 & 0.010 & 0.049 \\
\hline $\mathrm{C} 24$ & 0.112 & 0.537 & 0.043 & 0.037 \\
\hline $\mathrm{C} 25$ & 0.071 & -0.026 & 0.057 & -0.249 \\
\hline C26 & 0.177 & 0.578 & 0.077 & 0.119 \\
\hline $\mathrm{C} 27$ & 0.131 & 0.520 & 0.108 & 0.105 \\
\hline C28 & 0.109 & 0.672 & -0.002 & 0.030 \\
\hline
\end{tabular}

(Continued)
TABLE A3 | Continued

\begin{tabular}{|c|c|c|c|c|}
\hline \multicolumn{5}{|c|}{ Component } \\
\hline & 1 & 2 & 3 & 4 \\
\hline C29 & 0.200 & 0.525 & 0.245 & 0.191 \\
\hline C30 & 0.066 & 0.515 & 0.049 & 0.105 \\
\hline C31 & 0.203 & 0.566 & 0.150 & 0.142 \\
\hline C32 & 0.206 & 0.586 & 0.120 & 0.082 \\
\hline C33 & 0.167 & 0.592 & 0.107 & 0.111 \\
\hline C34 & 0.116 & 0.491 & -0.008 & 0.080 \\
\hline P35 & 0.356 & 0.156 & 0.257 & 0.473 \\
\hline P36 & 0.345 & 0.189 & 0.267 & 0.486 \\
\hline P37 & 0.334 & 0.174 & 0.235 & 0.481 \\
\hline P38 & 0.365 & 0.159 & 0.271 & 0.464 \\
\hline P39 & 0.288 & 0.046 & 0.257 & 0.461 \\
\hline P40 & 0.330 & 0.134 & 0.255 & 0.491 \\
\hline P41 & 0.348 & 0.050 & 0.358 & 0.513 \\
\hline P42 & 0.278 & -0.007 & 0.247 & 0.460 \\
\hline P43 & 0.384 & 0.212 & 0.184 & 0.457 \\
\hline P44 & 0.373 & 0.240 & 0.140 & 0.451 \\
\hline P45 & 0.309 & 0.105 & 0.162 & 0.431 \\
\hline P46 & 0.371 & 0.108 & 0.245 & 0.545 \\
\hline P47 & 0.385 & 0.137 & 0.197 & 0.523 \\
\hline P48 & 0.400 & 0.120 & 0.203 & 0.506 \\
\hline P49 & 0.404 & 0.136 & 0.227 & 0.485 \\
\hline P50 & 0.033 & -0.093 & 0.113 & -0.263 \\
\hline SRL51 & 0.568 & 0.181 & 0.177 & 0.160 \\
\hline SRL52 & 0.466 & 0.155 & 0.140 & 0.063 \\
\hline SRL53 & 0.611 & 0.201 & 0.168 & 0.152 \\
\hline SRL54 & 0.581 & 0.136 & 0.258 & 0.179 \\
\hline SRL55 & 0.610 & 0.159 & 0.208 & 0.206 \\
\hline SRL56 & 0.631 & 0.200 & 0.160 & 0.106 \\
\hline SRL57 & 0.644 & 0.216 & 0.057 & 0.085 \\
\hline
\end{tabular}


TABLE A3 | Continued

\begin{tabular}{lcccc}
\hline \multicolumn{5}{c}{ Component } \\
\hline & $\mathbf{1}$ & $\mathbf{2}$ & $\mathbf{3}$ & $\mathbf{4}$ \\
\hline SRL58 & $\mathbf{0 . 6 2 7}$ & 0.301 & 0.096 & 0.054 \\
SRL59 & $\mathbf{0 . 5 1 9}$ & 0.213 & 0.052 & 0.068 \\
SRL60 & $\mathbf{0 . 5 8 3}$ & 0.178 & 0.300 & 0.083 \\
SRL61 & $\mathbf{0 . 5 8 0}$ & 0.165 & 0.177 & 0.037 \\
SRL62 & $\mathbf{0 . 6 2 7}$ & 0.132 & 0.286 & 0.167 \\
SRL63 & $\mathbf{0 . 6 2 3}$ & 0.109 & 0.288 & 0.169 \\
SRL64 & $\mathbf{0 . 4 7 4}$ & 0.141 & 0.147 & 0.061 \\
SRL65 & $\mathbf{0 . 4 6 9}$ & 0.115 & 0.121 & 0.053 \\
SRL66 & $\mathbf{0 . 5 6 3}$ & 0.125 & 0.254 & 0.225 \\
SRL67 & $\mathbf{0 . 5 8 6}$ & 0.124 & 0.260 & 0.209 \\
SRL68 & $\mathbf{0 . 5 9 8}$ & 0.200 & 0.207 & 0.145 \\
SRL69 & $\mathbf{0 . 4 8 6}$ & 0.204 & 0.152 & 0.075 \\
SRL70 & $\mathbf{0 . 5 3 7}$ & 0.197 & 0.213 & 0.187 \\
\hline
\end{tabular}

TABLE A4 | Item to Total Correlation Coefficient of ASES-FJHS Final Form.

\begin{tabular}{|c|c|c|}
\hline & $\begin{array}{l}\text { Corrected item- } \\
\text { total correlation }\end{array}$ & $\begin{array}{l}\text { Cronbach's alpha if } \\
\text { item deleted }\end{array}$ \\
\hline PC1 & 0.528 & 0.955 \\
\hline PC2 & 0.456 & 0.955 \\
\hline PC3 & 0.476 & 0.955 \\
\hline PC4 & 0.477 & 0.955 \\
\hline PC5 & 0.348 & 0.956 \\
\hline PC6 & 0.467 & 0.955 \\
\hline PC7 & 0.507 & 0.955 \\
\hline PC8 & 0.441 & 0.955 \\
\hline PC9 & 0.462 & 0.955 \\
\hline $\mathrm{PC} 10$ & 0.463 & 0.955 \\
\hline PC11 & 0.442 & 0.955 \\
\hline PC12 & 0.426 & 0.955 \\
\hline $\mathrm{C} 13$ & 0.428 & 0.955 \\
\hline C14 & 0.570 & 0.955 \\
\hline C15 & 0.508 & 0.955 \\
\hline C16 & 0.442 & 0.955 \\
\hline C17 & 0.340 & 0.956 \\
\hline C18 & 0.337 & 0.956 \\
\hline C19 & 0.447 & 0.955 \\
\hline C2O & 0.400 & 0.955 \\
\hline C21 & 0.379 & 0.955 \\
\hline C22 & 0.542 & 0.955 \\
\hline C23 & 0.327 & 0.956 \\
\hline C24 & 0.501 & 0.955 \\
\hline C25 & 0.477 & 0.955 \\
\hline C26 & 0.460 & 0.955 \\
\hline C27 & 0.313 & 0.956 \\
\hline P28 & 0.578 & 0.955 \\
\hline P29 & 0.597 & 0.955 \\
\hline P30 & 0.566 & 0.955 \\
\hline P31 & 0.590 & 0.955 \\
\hline P32 & 0.479 & 0.955 \\
\hline Р33 & 0.561 & 0.955 \\
\hline P34 & 0.587 & 0.955 \\
\hline P35 & 0.442 & 0.955 \\
\hline P36 & 0.585 & 0.955 \\
\hline P37 & 0.569 & 0.955 \\
\hline P38 & 0.466 & 0.955 \\
\hline P39 & 0.591 & 0.955 \\
\hline P40 & 0.577 & 0.955 \\
\hline P41 & 0.578 & 0.955 \\
\hline
\end{tabular}

(Continued)
TABLE A4 | Continued

\begin{tabular}{lcc}
\hline & $\begin{array}{c}\text { Corrected item- } \\
\text { total correlation }\end{array}$ & $\begin{array}{c}\text { Cronbach's alpha if } \\
\text { item deleted }\end{array}$ \\
\hline P42 & 0.590 & 0.955 \\
SRL43 & 0.574 & 0.955 \\
SRL44 & 0.441 & 0.955 \\
SRL45 & 0.604 & 0.955 \\
SRL46 & 0.603 & 0.955 \\
SRL47 & 0.622 & 0.955 \\
SRL48 & 0.594 & 0.955 \\
SRL49 & 0.556 & 0.955 \\
SRL50 & 0.591 & 0.955 \\
SRL51 & 0.465 & 0.955 \\
SRL52 & 0.610 & 0.955 \\
SRL53 & 0.526 & 0.955 \\
SRL54 & 0.642 & 0.954 \\
SRL55 & 0.631 & 0.955 \\
SRL56 & 0.444 & 0.955 \\
SRL57 & 0.416 & 0.955 \\
SRL58 & 0.604 & 0.955 \\
SRL59 & 0.617 & 0.955 \\
SRL60 & 0.611 & 0.955 \\
SRL61 & 0.488 & 0.955 \\
SRL62 & 0.588 & 0.955 \\
\hline
\end{tabular}

TABLE A5 | Split-half correlations of ASES Final Form.

\section{Reliability statistics}

\begin{tabular}{llll}
\hline Cronbach's Alpha & Part 1 & $\begin{array}{l}\text { Value } \\
\text { No of Items } \\
\text { Value } \\
\text { No of Items }\end{array}$ & $\begin{array}{l}0.905 \\
31^{\mathrm{a}} \\
0.940 \\
31^{\mathrm{b}}\end{array}$ \\
\hline Correlation between forms & Total No of Items & 62 \\
\hline Spearman-Brown coefficient & Equal length & 0.763 \\
\hline Guttman Split-Half Coefficient & Unequal length & 0.865 \\
& & 0.865 \\
\hline
\end{tabular}

